\begin{tabular}{|l|l|}
\hline Incendiar el océano. Notas sobre la(s) recepción(es) de Althusser en Cuba & Titulo \\
\hline Ortega Reyna, Jaime - Autor/a; & Autor(es) \\
\hline $\begin{array}{l}\text { De Raíz Diversa. Revista Especializada en Estudios Latinoamericanos (Vol. 2 no. 4 } \\
\text { jul-dic 2015) }\end{array}$ & En: \\
\hline México D.F. & Lugar \\
\hline $\begin{array}{l}\text { Programa de Posgrado en Estudios Latinoamericanos, Universidad Nacional } \\
\text { Autónoma de México }\end{array}$ & Editorial/Editor \\
\hline 2015 & Fecha \\
\hline $\begin{array}{l}\text { Rodríguez Ugidos, Zaira; Martínez Heredia, Fernando; Revolución cubana; Althusser, } \\
\text { Louis; Díaz Castañón, María del Pilar; América Latina; Cuba; }\end{array}$ & Temas \\
\hline Artículo & Colección \\
\hline $\begin{array}{l}\text { "http://biblioteca.clacso.edu.ar/Mexico/ppel-unam/20160627033728/Jaime_Ortega._Incendiar_el_oceano._Notas_sobre_las_recepciones } \\
\text { de_Atthusser_en_Cuba.pdr" }\end{array}$ & URL \\
\hline $\begin{array}{l}\text { Reconocimiento-No Comercial-Sin Derivadas CC BY-NC-ND } \\
\text { http://creativecommons.org/licenses/by-nc-nd/2.0/deed.es }\end{array}$ & Licencia \\
\hline
\end{tabular}

Segui buscando en la Red de Bibliotecas Virtuales de CLACSO http://biblioteca.clacso.edu.ar

Consejo Latinoamericano de Ciencias Sociales (CLACSO)

Conselho Latino-americano de Ciências Sociais (CLACSO)

Latin American Council of Social Sciences (CLACSO)

www.clacso.edu.ar

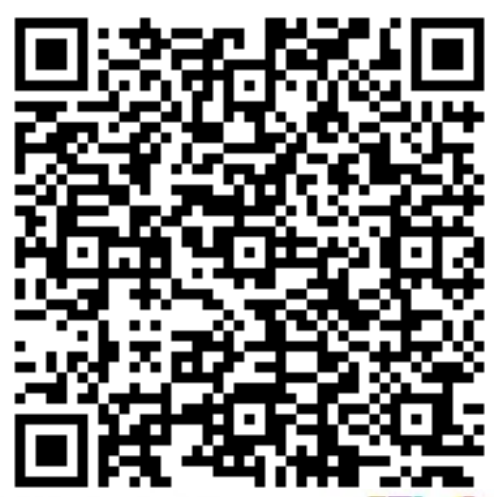

Consejo Latinoamericano de Ciencias Sociales

Conselho Latino-americano de Ciências Sociais 


\title{
Incendiar el océano. Notas sobre la(s) recepción(es) de Althusser en Cuba*
}

\author{
Jaime Ortega ReynA**
}

Resumen: La obra teórica de Louis Althusser encontró en los años inmediatamente posteriores a la revolución cubana un espacio de recepción crítica inigualable. A través de traducciones, publicaciones y polémicas, Althusser fue difundido en la Cuba socialista de manera constante. El presente artículo busca articular la recepción crítica que se hizo de su obra a partir de tres momentos, poniendo énfasis en las obras de Fernando Martínez Heredia, Zaira Rodríguez y María del Pilar Díaz. Un autor y dos autoras que discutieron, criticaron y asimilaron la propuesta del "althusserianismo" según las coordenadas teóricas en las que se produjo su lectura.

Palabras Clave: Althusser, marxismo, revolución cubana.

Aвstract: The theoretical work of Louis Althusser found an unmatched space of critical reception in the years immediately following the Cuban revolution. Through translations, publications and polemics, Althusser had been constantly diffused in the socialist Cuba. This article seeks to articulate the critical reception of his writings emphasizing the works of Fernando Martinez Heredia, Zaira Rodriguez and Maria del Pilar Diaz, of one male and two female authors that discussed, criticized and assimilated differently the proposal of "althusserianism" depending on the theoretical climate in which occurred its reading.

KEYWORDS: Althusser, marxism, Cuban revolution.

RECiBIDO: 04 de mayo de 2015. Aceptado 20 de mayo de 2015.

E

n el presente texto queremos trabajar sobre tres registros que en un momento específico se han encontrado girando alrededor de una misma temática: la recepción de Althusser que se hace fuera de Europa, específicamente en América Latina y en la particularidad del marxismo

El presente texto se realizó como becario pos-doctoral de la Coordinación de Humanidades en el CiAlc donde lleva adelante una investigación sobre la recepción de Althusser en América Latina y el Caribe.

** Pos-doctorante del Centro de Investigaciones sobre América Latina y el Caribe (CIALCunam) con una beca de la Coordinación de Humanidades. Agradezco a las y los compañeros del proyecto PAPIIT IN-30071 por sus comentarios.<jaime_ortega83@hotmail.com> 
desarrollado en Cuba. Las vicisitudes que se generan a partir de una "coyuntura", cuando esta encuentra en una obra múltiples posibilidades de producción de conocimiento o bien una oportunidad de distanciamiento y de crítica de ella son el objeto de nuestro interés. El arribo de Althusser a Cuba, será un síntoma de las transformaciones que acontecen al seno del pensamiento crítico, de la relación de éste con una realidad política en transformación, quizá en el movimiento más estridente de nuestra región: la propia revolución acontecida en Cuba.

En las siguientes páginas abordaremos lo que nos parece es lo más significativo de dicha recepción a través de las obras de tres autores en momentos diversos: Fernando Martínez Heredia, Zaira Rodríguez Ugidos y María del Pilar Díaz Castañón. Tres autores íconos del pensamiento filosófico cubano posterior a la revolución de 1959. Colocados en coyunturas políticas y filosóficas diversas generaron una lectura crítica original, tanto al interior de la trayectoria del pensamiento cubano como de la otros esfuerzos en América Latina. La obra de Althusser fue una luz que iluminaba cuestiones teóricas importantes, al tiempo que oscurecía otras, pero nunca un rayo cegador que creara un nuevo canon. Si bien no se trata de los únicos pensadores que incorporaron de alguna manera a Althusser en sus reflexiones, sin duda son de los máximos exponentes que encontraremos en Cuba. Dividiremos nuestra exposición en cuatro secciones. En la primera de ellas trataremos de develar la especificidad cubana de la recepción de Althusser, sus similitudes y sus distancias con el resto de América Latina.

En la segunda, abordaremos la época en donde Fernando Martínez Heredia junto a otros jóvenes intelectuales incursionaron en la crítica a Althusser a partir de experiencias colectivas como la revista Pensamiento Crítico y el Departamento de Filosofía en la Universidad de La Habana.

En tercer lugar, abordaremos el conjunto de críticas que en el trabajo de la filósofa Zaira Rodríguez se expusieron en la única obra de conjunto dedicada a dicha temática, señalando la especificidad de la crítica: cuando Cuba se volvió un país más cercano a la Unión Soviética. Finalmente, expondremos la lectura reciente de María del Pilar Díaz, quien sigue enseñando en la Universidad de La Habana y es un referente indudable para asediar críticamente la obra del filósofo francés.

Hace poco más de una década la profesora Natasha Gómez dedicó una publicación a los "primeros encuentros" del pensamiento cubano con Althusser (Gómez: 2002). Más que contradecir o matizar elementos de 
dicho texto, el nuestro pretende ser un complemento a aquel esfuerzo. Gómez escudriña de manera muy concienzuda esos primeros años de la coyuntura revolucionaria. El esfuerzo que la profesora cubana realizó sin duda es central para cualquier estudioso de la recepción no sólo de dicho pensador, sino del marxismo en las revistas cubanas, tema al que dedicó su tesis doctoral.

\section{ALTHUSSER EN AMÉRICA LATINA: LA ESPECIFICIDAD CUBANA}

Con todo el sentido que tiene el uso de la palabra en el lenguaje del filósofo francés, podemos referirnos justamente a la "coyuntura" cubana. Un momento muy particular de la historia de América Latina en donde la teoría marxista no partía de una vanguardia, sino que era un proceso de creación dentro del propio movimiento político. Un proceso de creación que además reclamaba cierta originalidad y una búsqueda por romper con cualquier colonialismo intelectual, razón esta que obligaba a dialogar como iguales y no a subordinarse a-críticamente. La revolución cubana fue un momento de renovación radical del pensamiento de la izquierda en el continente, así lo reconocen los artífices de la teoría de la dependencia o de la filosofía de la liberación, por mencionar algunas variantes que siguen trastocando, a su manera, nuestra reflexión. Fue un momento también de posibilidad de plantear de modo radical vías alternas al modelo del socialismo realmente existente, justamente al abrir múltiples posibilidad de transitar al socialismo. Un periodo de improvisación política pero también de entusiasmo entre la juventud, de renovación de los viejos dirigentes comunistas y de formación de una nueva generación, cuyo horizonte era una pequeña isla a unos pocos kilómetros de los Estados Unidos, pero cuyo impacto dislocó el orden simbólico de la geo-política mundial.

Es en ese contexto en el que debemos ubicar el momento de recepción de la obra del filósofo y militante comunista Althusser. Comparada a la atención que ha recibido la presencia de otros autores europeos heréticos de la tradición marxista, como por ejemplo Antonio Gramsci, el caso de Althusser apenas comienza a ser estudiado. Su influencia es muy parecida a la del pensador italiano, lo que ha llevado a algunos a insistir que la presencia de Althusser fue un filtro para conocer a Gramsci. Sin embargo este tipo de tesis tan generales tiene que ser matizada por estudios particulares que permitan reconstruir una visión de conjunto mucho más acorde con 
la especificidad de los procesos políticos y culturales. Justamente ese es nuestro propósito principal y el de otros estudiosos en tiempos recientes.

Dentro de la joven línea de investigación en torno a la recepción de dicho autor, podemos mencionar los casos de Chile y Argentina como los más avanzados hasta este momento. Ana Popovich por ejemplo ha realizado un amplio esfuerzo por localizar el lugar que tenía Althusser en la revista argentina Los Libros, señalando los cruces que hay entre la lectura política y las corrientes psicoanalíticas, tan importantes en ese país, particularmente para lo que la autora denomina como la "Nueva izquierda argentina" (Popovich: 2012). Por su parte, en una línea un poco más amplia los trabajos de Marcelo Starcenbaum indagan tanto en la presencia de Althusser en la revista Pasado y Presente, como en la colección de libros que llevaban el mismo título. Starcenbaum en dicho trabajo ha señalado la presencia organizadora de "Los cuadernos Althusser", como aquellos que dotan al grupo encabezado por José Aricó de un sentido a partir de nudos problemáticos específicos (Starcenbaum: 2011). En un registro distinto, más allá de las experiencias intelectuales, Starcenbaum ha rastreado la presencia del filósofo francés en la formación de un grupo guerrillero, las Fuerzas Argentinas de Liberación (Starcenbaum: 2011 a). En el caso de Chile la recepción y la problematización de ella a partir de registros como el historiográfico ha sido ensayada por Miguel Valderrama (1988) y en tiempos más recientes por un grupo de jóvenes filósofos (Rodríguez: 2013) En el caso de México tenemos el primigenio recuento que hizo Cesáreo Morales a propósito de las distintas lecturas que se ensayaron en el tránsito de los años sesenta a los setenta (Morales: 2008) el otro trabajo relevante ha versado sobre la presencia de Althusser en la tesis de licenciatura del Subcomandante Insurgente Marcos (Sáez: 2012).

La posibilidad de un acercamiento más global a la recepción de la obra de Althusser aún está en ciernes, sin embargo, contamos con algunas posibilidades de narrar la forma en que se dio en esos países con respecto a lo que hemos denominado la "coyuntura cubana". Un primer comienzo de esta contrastación se da con un dato relevante: las fechas de la publicación de algunos de los artículos y libros del filósofo francés. Si bien es cierto que la mayor parte de la obra de Althusser se conoce a nivel continental a partir de la intervención que Martha Harnecker realiza como traductora, siendo publicados en 1967 varios de sus ensayos con el título de $L a$ revolución teórica de Marx y con el título de Para Leer El Capital en 1969 los trabajos de Althusser y Balibar del famoso seminario llevado en la 
Escuela Normal en donde se propone realizar una lectura filosófica del texto de Marx. En Cuba en cambio se publicó en el año 1966 la edición de Por Marx, esto es, un año antes de la famosa edición que publicara Siglo XXI, respetando el título original, en tanto que Leer El Capital se publicó en el mismo año, esto es, tres años antes de la versión más popular, con un doble añadido: se respeto el título original y se publicó de manera completa, tal como en la versión francesa, en dos tomos. De igual manera en el número 36 de la revista Casa de las América se publica "Teoría, práctica teórica y lucha ideológica", en febrero de 1966.

El segundo elemento que constituye la "coyuntura cubana" respecto a la impronta de Althusser y que comparativamente la vuelve distante a cualquier otro caso en América Latina, es sin duda la revolución y el auge que ella generó en los núcleos de pensamiento crítico. Si bien se podría pensar que la filosofía o el marxismo mismo no eran ejes centrales de una revolución que tenía que sobrevivir y soportar invasiones, amenazas reiteradas, boicots, lo cierto es que la figura de Althusser, como la de tantos otros intelectuales, representó un momento de redefinición de las coordenadas teóricas. No fue, ciertamente, el único. Ni Althusser, ni el marxismo occidental colonizaron el pensamiento cubano. Por el contrario, convivieron y fueron puestos a dialogar con la tradición martiana, la del pensamiento socialista cubano y latinoamericano en su conjunto e incluso con la ortodoxia soviética. Esta condensación de problemáticas no se encuentran de manera tan sencilla en otros espacios y experiencias de recepción. La revolución vuelve un ejemplar único de recepción la figura de un autor.

Las similitudes de la recepción de Althusser se encuentran en cambio en una dimensión valorativa distinta: la posibilidad de romper con las formas ortodoxas soviéticas que se cernían sobre los espacios de producción del marxismo cubano. La obra de Althusser operará en América Latina, según los estudios de los que podemos disponer, arriba citados, en el sentido de abrir el espacio a una joven generación que busca referentes más allá del canon soviético. Esto implica sobre todo y de manera particular a la formación de militantes por parte de la ortodoxia soviética. Esto ayuda o contribuye a salirse de los núcleos dominantes de los Partidos Comunistas, que tanto tardaron en valorar la experiencia de la propia revolución cubana. El althusserianismo latinoamericano, si se nos permite la licencia, es un hecho de comunistas por fuera de la forma partido. Es, por el contrario, una forma herética, comunista y radical. 


\section{PENSAMIENTO CRÍTICO Y EL EJERCICIO DEL PENSAR}

Una parte significativa de la recepción de Althusser se dio a través de la revista Pensamiento crítico y algunos proyectos aledaños a ella, particularmente dos muy significativos para la historia intelectual cubana: la fundación del Departamento de Filosofía a principios de los años sesenta y la publicación de El Caimán barbudo, bajo la dirección del después exiliado Jesús Díaz (Navarrete, 2012; 17-42) también a principios de aquella década. En todos ellos estuvo presente, junto a otros jóvenes intelectuales, Fernando Martínez Heredia. Fue en el contexto de la visita del entonces presidente Osvaldo Dórticos al Departamento de Filosofía que, según se recoge en una de las evaluaciones globales más importantes sobre el impacto de aquella época, éste les dijo a los jóvenes profesores de filosofía: "Bueno, ¿qué deben hacer? Yo no lo sé. Yo sólo les digo que hay que incendiar el océano. Ahora, cómo lo queman es un asunto de ustedes, lo tienen que descubrir ustedes" (Kohan, 2006: 402).

El incendio del océano, frase poderosa que convocaba a realizar lo que hasta entonces parece irrealizable, en realidad va en consonancia con una etapa del pensamiento cubano en el que se desarrollan una variedad impresionante de polémicas, no sólo políticas, sino también artísticas y culturales, en el ámbito de la literatura y del cine. Graziella Pologolotti quien ha reunido algunos de los textos más importantes de las distintas polémicas de la época sentencia:

La década estaba terminando en 1968. Con fuerte acento descolonizador y extensa pluralidad de voces, desde Siqueiros hasta quienes mantenían viva la memoria de Troski, desde los etnólogos seguidores de Michel de Leiris hasta Christiane Rochefort, el Congreso Cultural de La Habana se produjo después de la caída del Che en Bolivia y contenía los gérmenes de los movimientos de mayo. Tlatelolco y París parecían anunciar el ímpetu de una izquierda renovada. [...]En el plano interno, los esfuerzos se concentraban en el empeño por acelerar el crecimiento económico, mediante el desarrollo de la producción azucarera, proyectada hacia la voluntad de alcanzar diez millones de toneladas en 1970. Todas las ramas de la economía se volcaron hacia esa dirección fundamental a la vez que desaparecían los últimos vestigios de empresa privada. Sabido es que la meta no pudo ser alcanzada en una coyuntura conducente a privilegiar, por encima de diferencias de enfoque que nunca desaparecieron, la unidad del campo socialista. (Pogolotti, 2006: p. XXII) 
Es en este quiebre, en esta bifurcación histórica que tendrá la revolución cubana y el conjunto del pensamiento de izquierda que debemos ubicar la recepción de las obras de pensadores diversos de la tradición marxista. Puesto a dialogar con una tradición local y continental con la mira a forjar herramientas interpretativas más adecuadas, más originales y más poderosas que con las que se contaba.

Una primera parte de la exposición tiene que ver con la recepción en las revistas y espacios de discusión pública, particularmente en lo que se refiere a las actividades del grupo que se estructuró a partir de la revista Pensamiento Crítico. En la segunda se revisará el abordaje crítico que realizó Martínez Heredia.

La publicación de Althusser, se señaló antes, comenzó en 1966, con la traducción de las obras hasta entonces disponibles en Francia. El segundo momento de su publicación se dio en el seno de la revista Pensamiento Crítico, que pasó a ser una especie de extensión del recién fundado Departamento de Filosofía. Martínez Heredia ha contado en repetidas ocasiones la historia de la apertura y cierre de estos dos momentos claves del pensamiento marxista cubano y latinoamericano. Su apertura se dio en la coyuntura que posibilitó una intervención radical sobre la forma en la que se entendía el "marxismo-leninismo", a partir de varias claves: el pensamiento cubano, la reflexión anti-colonial y el marxismo occidental, así como una crítica al modelo soviético de enseñanza del marxismo, particularmente a los manuales. Se da por tanto un alejamiento del modelo del "HistMat" (Materialismo histórico) y el "DiaMat" (Materialismo dialéctico). Una apertura de investigación y un intento de revolución en el plano de la práctica teórica, de la producción de un nuevo sentido en lo que se entendía por "marxismo-leninismo" se dio en este momento, en tanto que era una necesidad vital para los jóvenes revolucionarios:

Los cubanos necesitábamos un pensamiento capaz de permitirnos comprender nuestras circunstancias y sobre todo de elevarnos por encima de ellas, de ayudarnos a forjar y a cambiar una y otra vez las actuaciones y las actitudes, las relaciones y las instituciones. Pensar cómo debían ser la economía, la política, la educación, la ética, para lograr mantener, defender y desarrollar este régimen opuesto al capitalismo (Dialéktica, 1993: 78)

Tanto Pensamiento Crítico como algunas de las actividades del Departamento de Filosofía permitieron satisfacer en cierta mediada esa necesidad de los jóvenes revolucionarios que querían "incendiar el océano". ¿Cómo se insertó Althusser? Como una pieza clave a la que se recurrió de 
manera crítica. El asedio de la obra de Althusser fue siempre marcado por una incorporación crítica y por distanciamientos de segmentos de la obra que eran inasibles para la experiencia revolucionaria que se vivía. En esto no hay ambigüedad alguna. No hubo, a diferencia de otros países como México, Argentina, Chile o Brasil, una "escuela althusseriana", o varias.

En todos estos casos algún o algunos intelectuales que pasaron por $\mathrm{Pa}$ rís regresaban a sus países con el entusiasmo de haber escuchado, leído y discutido al filósofo francés. Se volvían sus traductores, ampliaban "campos problemáticos" inaugurados por el filósofo de la Normal Superior o simplemente eran sus divulgadores. Casos muy importantes los encontramos en México con Raúl Olmedo, en Argentina con Emilio de Ípola, en Chile con Martha Harnecker. En el caso de la recepción acontecida en Cuba lo que tenemos es un diálogo entre jóvenes intelectuales revolucionarios, con una obra que los interpela. Aurelio Alonso, miembro del Departamento de Filosofía y de la renovación del pensamiento marxista testimonia esto:

Nosotros hicimos cosas en aquel Departamento de Filosofía viviendo también un proceso de transformación, de cambios. Con lecturas e influencias de otras corrientes, pero no es como muchos quisieron hacer ver, no es que de repente el Departamento se hiciera althusseriano. Esa es una mirada simplista y ajena a lo que sucedió realmente [...] Para nosotros, en 1965, la lectura de Althusser tuvo cierta importancia (González, 2006: 72).

El aporte de Althusser sería necesario en la disputa por la enseñanza del marxismo en los años sesenta. En ella se buscó desplazar la noción de "Filosofía marxista-leninista" en su división clásica y sistematizada como Materialismo Histórico y Materialismo Dialéctico heredada por la ortodoxia soviética. A ello se opuso una problematización de la propia historia del marxismo, en su contexto, génesis, rupturas y continuidades (Gómez, 2006: 110). Esa huida del HistMat y el DiaMat permitió que el Departamento de Filosofía y en gran medida el equipo que conformaba el consejo editorial de Pensamiento crítico, aportaran de manera decisiva en una renovación heterodoxa de concebir, enseñar y desarrollar el marxismo en Cuba. Para nuestros intereses es el marxismo de Althusser una de las piezas clave para dicha renovación. No es, por supuesto, la única ni la más importante, pero sí la que permite renovar algunos de los dispositivos conceptuales más candentes del marxismo. 
La recepción después de las dos obras reseñadas que se dio en los medios cubanos fueron las siguientes: en el número 5 de la revista Pensamiento Crítico, correspondiente a junio de 1967 se publicó el ensayo "Materialismo histórico y materialismo dialéctico", un ensayo que será fundamental para las escuelas althusserianas europea y latinoamericana. En ese mismo año, 1967, pero en el número 10 se publican dos cartas entre Althusser y André Daspre, a propósito del conocimiento artístico. La siguiente ocasión que Althusser aparece en la revista Pensamiento Crítico es en el número 34-35, con la publicación de la conferencia que dictó en la Sociedad de Filosofía de París, titulada "Lenin y la filosofía", como se sabe, un documento crucial para el pensamiento althusseriano que caminaba ya para su primera autocrítica. Junto al texto sobre Lenin apareció un texto crítico a cargo de Francois George, en el mismo número. Como dato aledaño en los números 7 y 8 correspondientes a agosto y septiembre del año 67 se publicó el texto de Nicos Poulantzas, reconocido deudor de la obra de Althusser, sobre la hegemonía en el Estado moderno. Además de estos espacios de recepción, cruciales desde nuestro argumento, hubo un par más que vale la pena señalar.

El equipo de la revista ocupó también un espacio importante en el Departamento de Filosofía a través del cual en 1968 se publicaron dos tomos denominados Lecturas de Filosofía. Dichas publicaciones buscaban romper con el esquema del "Manual" de tipo soviético. Pero además se disolvía la clásica ruptura, señalada como "HistMat" y "DiaMat". En lugar de ello y al igual que la revista, se operaba un cambio temático: además de los llamados clásicos del marxismo aparecían temas como la des-colonización, el estudio de la filosofía (no marxista) y un tema que se desatará con pasión a partir de la escuela althusseriana: la categoría de formación social. En las Lecturas se incluían dos textos de Althusser: el llamado "Anexo" a "Contradicción y "superdeterminación" (así traducido en Cuba el término que en el resto de las ediciones en español será conocido como "sobre-determinación") y fragmentos del texto aparecido en la revista Casa de las Américas: “Teoría, práctica teórica y formación teórica” ya señalado arriba. El texto de "Contradicción y superdeterminación" también fue publicado en otro espacio frecuentado por los jóvenes revolucionarios de los que hemos hablado: El Caimán Barbudo, seguido de un comentario de Martínez Heredia, que desgraciadamente no hemos podido consultar. La última publicación de la que tenemos conocimiento es la que se publicó en el diario Unión, en su número 2 correspondiente a junio de 1969, se 
trata de la entrevista que Althusser concedió a la Nouvelle Critique, publicada en español como "La filosofía como arma de la revolución". Sobre la recepción que tuvo Althusser en el Caimán Barbudo el trabajo de Liliana Martínez (2006: 111-139) resulta esclarecedor, pues señala algunas de las principales críticas que de otros espacios de discusión se lanzaba a los intelectuales cubanos que buscaban incorporar a Althusser a su reflexión.

Para evaluar la recepción que se hace del filósofo francés tenemos que referirnos a dos textos que Martínez Heredia redacta en esta época y muestran un cambio en la recepción de Althusser. Se trata del texto "El ejercicio del pensar", publicada originalmente en Caimán Barbudo y reproducido en las Lecturas de Filosofía. Es éste el texto central para el filosofar en revolución, que Martínez Heredia ofreció en aquel momento, en disputa con quienes insistían en la repetición de ciertos moldes soviéticos. Un texto influido por las claves heredadas por Gramsci en la filosofía de la praxis, pero articulada en un lenguaje y preocupaciones de corte althusseriano, notables en la escritura del texto.

En "El Ejercicio del pensar" publicado en aquellas lecturas del 68 se muestra una clara influencia althusseriana en la escritura y en la centralidad que tienen las distintas prácticas sociales en la transformación política. En ese sentido la teoría se presenta como elemento exterior o bien posterior al movimiento revolucionario. Tómese en cuenta cómo no existe sobrevaloración teoricista en Martínez, sin embargo se da autonomía a la dimensión teórica. En ese sentido es que el propio autor insistirá en la necesidad de que los intelectuales, en el argot de la época el "trabajador intelectual”, haga autocrítica de sus posiciones privilegiadas. Sin embargo, al poner en el centro una concepción de diversas prácticas es que en algunas situaciones específicas de desarrollo teórico y de su relación con "objetivos prácticos" se subraya que "la teoría es reconocida como una práctica determinada" (Martínez, 1968, : II, 785). Con estos elementos me parece factible decir que "El ejercicio del pensar" es un texto en diálogo con la corriente althusseriana, siempre insistiendo tanto en la dimensión ideológica del marxismo como en la dimensión teórica, en tanto que "práctica teórica" y en tanto que "producción teórica". Práctica y producción teóricas son elementos utilizados por el Althusser de los primeros años para denostar al historicismo y las "filosofías de la praxis". Con dichos conceptos se distanciaba de quienes veían el conocimiento como un "descubrimiento" de apariencias ocultas e insistía en que la epistemología 
marxista era ante todo de producción de conceptos que captaban la especificidad del objeto de conocimiento.

Sin embargo lo que más llama la atención es sostener la hipótesis de la exterioridad del movimiento obrero con respecto a la teoría. Dicha exterioridad "no debe oscurecer, sin embargo, una realidad: la identificación con los intereses de clase proletarios, actitud práctica revolucionaria que deviene intuición apasionada e hipótesis del trabajo teórico.." (1968: II, 778)

Otro de los elementos fundamentales que opera en el texto de Martínez Heredia es la noción de que la teoría sustenta y establece, diría Althusser, una "línea de demarcación" que permite distinguir la "ciencia" de la ideología. Dice Heredia: "La teoría brinda certeza a las aseveraciones de la ideología, da fe de que el interés se corresponde con la "verdad", con la ciencia o con el "determinismo"...." Un tema que en esa época tomará cuerpo en la producción althusseriana era justamente ese: determinar la relación ciencia e ideología, marcar las líneas de determinación entre una y otra. En un párrafo muy singular y propio de esa recepción crítica dice: "En el plan estrictamente teórico se introdujo el antidogmatismo, el antistalinismo, el humanismo, la enajenación; pero no se produjo una investigación de los factores estructurales, del papel del partido en la revolución antiimperialista latinoamericana, de la correlación de los factores subjetivos y objetivos, de las relaciones entre clase y nación" (1968: II, 778).

Contextualizando la intervención de Martínez Heredia habría que señalar el texto "Orígenes del marxismo" incluido en el tomo primero de las "Lecturas de Filosofía". Si bien se trata de un trabajo muchísimo más breve y menos denso que "El Ejercicio del Pensar", se trata de textos en diálogo. Ahí Heredia deja clara, asumiendo algunas de los postuladores del althusserianismo, la forma del tránsito de la obra de Marx. Esto es, no sólo el contexto de su producción, sino además las propias divisiones al seno de una obra que no podría ser aquilatada de manera equivalente en sus partes. Contra la idea de una valoración desigual del marxismo, Heredia muestra las diversas fases que tiene la obra de Marx. Su evaluación respecto a los primeros textos son muy evidentes, escribe sobre la "concepción feuerbachiana del hombre", por ejemplo.

Como era habitual en la época se ubica la parte madura de Marx, esto es, una concepción no ideológica de las relaciones sociales y de los seres humanos con el advenimiento de la Ideología Alemana, donde "se expone por primera vez la nueva concepción” (Martínez, 1968: I, 124). Dicha concepción "novedosa", que rompería con la ideología anterior señala el 
nuevo derrotero tomado por el teórico alemán: “No queda ya lugar para la pérdida y el re-encuentro de la esencia humana, para Marx, la comprensión de la vida social surge de la investigación de una formación social determinada, en que se enfrentan las actividades económicas, políticas e ideológicas de las clases" (1968: I, 125). En una nota aledaña al texto se hace una valoración de la diferencia que supone una lectura del joven Marx (al cual dedicaron un seminario de estudio desde los primeros años sesenta) en Europa con respecto a Cuba. Y aunque le parece que en Cuba el término "humanismo" debe ser comprendido en el contexto no de un debate académico, sino de una coyuntura revolucionaria, también zanja una distancia en contra de algunas nociones de fácil uso:

Creo que enajenación" y "revolución humana" son conceptos suficientemente imprecisos como para que su uso actual sobre problemas actuales pueda ser positivo o negativo. Asimismo, el debate en torno a la teoría del estado está forzosamente influido por una concepción acerca de las relaciones entre democracia y socialismo que no corresponde a la experiencia nuestra. (1968: I, 127)

Como se puede observar, hay una recepción positiva del marxismo en clave althusseriana, pero no una capitulación a sus consecuencias prácticas. En dicho encuadre se establecía una "línea de demarcación" entre la lectura del humanismo del joven Marx y se le contraponía un "anti-humanismo teórico", en el sentido que se deslindaban los elementos ideológicos o a-históricos de dichos planteamientos, al mismo tiempo la experiencia revolucionaria propiciaba la posibilidad de un "humanismo práctico" que no pasaba tanto por la lectura sin más del joven Marx, sino por la experiencia propia.

La cercanía que se puede inferir de dichos textos con Althusser, sin embargo, pronto terminaría. El propio Martínez Heredia, en esta ocasión en las páginas de Pensamiento Crítico marcaba la distancia más grande con las concepciones del filósofo francés (1970: 210-218). Señalaba las inconsistencias de un pensamiento anclado en el giro "reformista" del comunismo europeo, aunque parecía practicar una especie de discurso radical, éste no se salía de aquel marco político que encerraba a los partidos comunistas de Europa Occidental. En segundo lugar quizá de manera más radical, Martínez Heredia señalaba la inconsecuencia de la gran pretensión teórica del althusserianismo:

Esto sucede porque el filósofo "no ha cambiado de elemento". Aunque condene violentamente el humanismo teórico, permanece en el campo de su 
problemática, proponiendo a la larga un sistema alternativo que enriquece en vez de negar, a través de la ampliación de posiciones producida por una crítica que deja en pie a los fundamentos del humanismo marxista (Martínez: 1970, 210-218).

En el texto que señalamos ahora, titulado "El Marxismo de Althusser" además se emprendía una fuerte crítica a un elemento que se ubicará en esta etapa de la producción del filósofo francés: su exceso de cientificismo. Este elemento será crucial para el distanciamiento que hará Martínez Heredia.

El desplazamiento crítico se da en consonancia con una mayor presencia del pensamiento de otros autores, no sólo del marxismo occidental, pero que en tenor con dicha corriente se oponían a Althusser. El giro que dará Martínez Heredia y otros en su pensamiento, aunque suspendido por la difícil década de los setenta, será finalmente no hacia Althusser, sino en dirección un autor criticado por éste: Gramsci.

\section{LOS AÑOS OCHENTA: LA CRÍTICA SOVIÉTICA DEL ALTHUSSERIANISMO.}

Después de la primavera intelectual que supuso la revista Pensamiento Crítico y el conjunto de proyectos alrededor del Departamento de Filosofía sobrevino un periodo más difícil para la reflexión crítica, en clave marxista u en otras. El propio Martínez Heredia ha señalado la existencia de éste periodo difícil para el pensamiento radical a partir del año 1971. El giro que la dirección de la revolución dio fue en un tono más conservador. En términos de la coyuntura esto significa que los espacios autónomos de reflexión y pensamiento se cerraron, para dar paso a un apego más cercano a la matriz soviética de entender y practicar el socialismo. Si bien esto no supuso una "sovietización" radical del país, lo cual debe entenderse como que Cuba no era una "colonia", sí hubo un conjunto de directrices que volvieron a Cuba un país dependiente de la urss. Esto que tenía una cierta explicación en cuanto al ritmo impuesto por la Guerra Fría, particularmente en la necesidad de la defensa del país frente a los Estados Unidos, significó un cambio radical al seno del pensamiento crítico.

El advenimiento de esta etapa, señalada por Martínez Heredia como un proceso de retroceso, que se volvió un "...cuadro de dogmatización y empobrecimiento del pensamiento marxista” (Martínez y Acanda, 1997: 21), supuso por su parte una mayor difusión de los manuales soviéticos y por otro el quiebre de una tradición que se venía forjando en los años sesenta. 
Cientos de libros fueron traducidos en los años setenta sobre la base de la forma soviética de comprender el marxismo, el socialismo y el resto de los elemento culturales significativos. Frente al pasado inmediato, es claro el retroceso. La economía política era entendida no cómo crítica, sino como "economía socialista"; cuyo eje programático era el problema de la "planificación socialista". En términos filosóficos las versiones contemporáneas del Diamat ganaron terreno. La "lógica dialéctica" y la "dialéctica materialista" pasaron a sustituir los referentes previos del pensamiento marxista cubano. En este contexto las aportaciones de un Jean Paul Sartre (por entonces ya distanciado de la revolución), un Gyorgy Lukács, un Karl Korsch o un Antonio Gramsci pasaban a un segundo orden o al franco olvido. Un autor que realiza una valoración del pensamiento marxista escribe:

La entrada de Cuba en el CAME y la intensificación de las relaciones económicas con el campo socialista, se tradujo en una validación de muchas de las características del modelo socialista soviético, en el que la teoría marxista cumplía la función de ideología "oficial", sustentadora del régimen político, más que la función crítica del conocimiento transformador de la realidad. En la enseñanza universitaria se estableció el esquema soviético del marxismo, como un conjunto de verdades que fundamentaban el camino ineluctable y ascendente de la sociedad universal hacia el socialismo, junto a la aceptación única de la comprensión de esta teoría como un sistema filosófico cerrado, formado por dos cuerpos: el materialismo dialéctico y el materialismo histórico. Los manuales sustituyeron el estudio de El capital, se desconoció la historia del pensamiento marxista y de los diferentes marxistas, y tendió a primar la comprensión de la Revolución cubana - y aun de la propia historia insular - como un ejemplo que validaba las "leyes generales de la historia". En consecuencia, decayó el interés por el estudio de la cultura nacional, aunque la dirigencia política continuo su adscripción a sus fuentes patrióticas, en especial a Martí, y los intelectuales marxistas ya formados continuaron evidenciando en su producción escrita su interés por aquella. (Rodríguez, s/f)

Sin duda alguna las valoraciones de este periodo en el pensamiento y la producción de conocimiento están aún por realizarse. Sería un juicio histórico injusto pretender que el acercamiento más cercano a la URss significó inmediatamente un sofocamiento de un pensamiento poderoso e importante para las distintas coyunturas abiertas en el tercer mundo. A pesar del acercamiento al sovietismo más extremo, Cuba nunca perdió su ánimo anti imperialista, descolonizador y revolucionario.

En este contexto es posible plantear un nuevo tipo de acercamiento al pensamiento de Louis Althusser. Se trata de una versión mucho más críti- 
ca, menos tendiente a crear puentes y con un diálogo prácticamente roto a partir del advenimiento de las corrientes soviéticas más "ortodoxas". Para ello evaluaremos en este periodo las críticas de una filósofa cubana de gran importancia: Zaira Rodríguez Ugidos.

Rodríguez Ugidos nació en 1941 y para 1965 ya se había graduado como Doctora en Filosofía en la Universidad de La Habana, unos años después, mientras en Cuba se cerraba el experimento del Departamento de Filosofía, ella defendía su Candidatura a Doctora por la Universidad Lomonosov de Moscú. De 1971 a su deceso en 1985 fue uno de los pilares de la enseñanza de la filosofía en Cuba, una vez reorientada la estructura académica tras el cierre del antiguo Departamento. Su obra va y viene por los más variados temas: hace crítica de la lectura de Rodolfo Mondolfo a propósito del marxismo, prologa las obras escogidas de Feuerbach y se dedica al estudio y enseñanza de la obra de Marx y Engels. Aunque, en la mejor tradición filosófica, su aporte sustancial se encuentra en los desarrollos a propósito de la "lógica dialéctica" que expuso en varias publicaciones, siguiendo el desarrollo de aquella temática explorado en la Unión Soviética

Respecto a Rodríguez Ugidos habrá que localizar la obra de calado más importante de crítica a Althusser junto a la obra que dedicara en México Adolfo Sánchez Vázquez. Sin embargo aunque ambos son ambiciosos y amplios estudios polémicos, parten de premisas diametralmente distintas. Rodríguez Ugidos asumirá a cabalidad todas las tesis de la filosofía soviética en boga, dedicando un primer capítulo de su obra justamente a la exposición de dicha concepción.

En adelante daremos la más sucinta exposición de la crítica que realiza dicha autora a Althusser, tratando de enmarcarla de acuerdo a los presupuestos del canon a partir del cual se realizaba dicha crítica. La filósofa cubana realiza una doble crítica. Para ella la obra de Althusser debe ser leída en dos momentos, uno de ellos lo denomina como el periodo "cientificista" (o teoricista) y el otro como el "practicista" (o anticientificista). La autora enmarca el contexto de las discusiones del filósofo francés con algunos de sus coterraneos y contemporáneos, sin detenerse mucho en ello, llamando mucho la atención la denominación que utiliza para algunos, por ejemplo cuando habla de "..los críticos de derecha [...] hacer mención de renegados del marxismo como Roger Garaudy y Henri Lefebvre" (Rodríguez, 1985: 94). Posterior a esa singular forma de referirse a los críticos pasa revista a la obra de Althusser, no tanto en cuanto a sus obras o textos, sino a propósito de la concepción de filosofía que él tiene. 
Podríamos decir que todo el discurso de la intelectual cubana se articula en torno a la concepción particular que de la filosofía Althusser tiene, en distintos periodos, ya señalados arriba.

El primer achaque que la autora realiza es que dentro de la concepción cientificista que Althusser proporciona de la filosofía de Marx, aquella que no existiría en cuanto cuerpo textual, sino en "estado práctico", esto es, aún por desarrollar, es que "reducía el pensamiento filosófico marxista a una suerte de conciencia crítica de las ciencias frente a las perpetuas amenazas de la ideología burguesa dominante" (1985: 99). Esto orillaba a Althusser a reconocer "la imposibilidad de concebir la filosofía marxista de forma positiva, esto es, dotada de un cuerpo teórico-conceptual y de un método propio" (1985: 99). Desde el punto de vista de la filósofa cubana la obra de Althusser cometía una herejía contra la "filosofía marxista leninista", que era separar al materialismo histórico (ciencia de la historia, ciencia de las formas sociales) del materialismo dialéctico (filosofía sin objeto, en estado práctico), dotando a este último de una forma puramente epistemológica, en tanto que guardián de la influencia ideológica burguesa sobre la ciencia. Para Rodríguez "Althusser establece una visión injustificada entre la teoría y el método filosófico" (1985: 105). El reproche central justamente da vuelta frente a lo que la ortodoxia soviética no permitía: dejar de considerar al marxismo como una cosmovisión, que totalizaba todas las formas del discurso filosófico, sin dejar posibilidad de excedente alguno. En términos de Rodríguez Althusser escindía la filosofía, separando epistemología, ciencia y método. El no-objeto de la filosofía que Althusser declaraba en Leer El Capital, era criticado por Rodríguez en los siguientes términos: "Así, la filosofía marxista tiene como tarea primordial y exclusiva liberar a las ciencias naturales y sociales del acoso ideológico" (1985: 110). Esta era una posición calificada como teoricista, en donde la filosofía marxista ya no era más el momento de la praxis, de la unidad teoría y práctica, puesto que escindía la cosmovisión totalizante del discurso marxista, que abarca todos los aspectos de la vida social, tanto en una dimensión material como "espiritual". Rodríguez no deja de señalar que al separar el materialismo histórico -en tanto que ciencia de la historia- del materialismo dialéctico -filosofía en ciernes- se coloca al primero como más relevante que el segundo.

Rodríguez realiza otras críticas menores desprendidas de esta centralidad. Por ejemplo le critica el concepto de práctica, que en Althusser resulta crucial una vez establecida la idea de la "práctica teórica", queriendo 
restaurar, en sintonía con la ideología soviética, una visión trascendental de la actividad humana, más allá de la especificidad discursiva. Restaura la autora entonces la visión trascendental e idealista de la unidad de teoría y práctica, explícitamente dicho: "cuando Althusser amplía el concepto de práctica hasta incluir en él otras formas de actividad espiritual, como son la actividad ideológica y la actividad teórico-científica, sólo obtiene con ello disolver el principio dialéctico materialista de la unidad de la teoría y la práctica" (1985: 116). Con ello para Rodríguez todo conocimiento comprueba su validez y veracidad en la praxis, en la unidad señalada. El concepto de práctica coloca los criterios de validación y verificación por fuera de dicha unidad. La teoría, de ahí el calificativo de teoricisimo, tendría su propia legalidad. El otro aspecto colateral que critica es el énfasis cientificista de este primer momento de la obra de Althusser, que ubica en el papel limitado que otorga a la filosofía con respecto a la ciencia y su relación con la ideología. Para la filósofa cubana la operación althusseriana consiste en expulsar la ideología del conocimiento científico, otorgando a éste un papel sobre-dimensionado a partir de su no incidencia en la política y en la toma de partido y de paso disminuyendo el papel de la "ideología proletaria”, que desde su punto de vista sería la científica. Para Rodríguez, Althusser construye un concepto supra-histórico y autónomo que no remite a la "forma de la conciencia social":

Pude plantearse que el teoricismo inherente a la primera etapa de la concepción althusseriana da lugar, por un lado, a una comprensión antidialéctica de la relación teoría-práctica, donde es la teoría la que representa el polo activo de esta relación, y por otro, a un cientificismo, que se manifiesta claramente en su concepción desideologizada de la filosofía como epistemología, y en su versión suprahistórica de la ciencia (1985: 135)

La valoración crítica de Althusser no se detiene ahí. La filósofa cubana insiste en el asedio a partir de lo que considera es un segundo bloque de la producción, marcado por la aparición de Lenin y la filosofía, El curso de filosofía para científicos y los Elementos de Autocrítica, en donde lo que a juicio de la autora dominará es un momento "practicista". De nuevo el punto de la crítica es el lugar de la filosofía. Ya no se tratará de una concepción en donde ésta se ubique "meta-teóricamente" como "teoría de las prácticas teóricas", sino que su papel quedará establecido a partir de su papel como establecedor de "líneas de demarcación". Las líneas de demarcación que la filosofía proporcionaría no sería un papel como productor de conocimiento, tampoco tendría un objeto específico de reflexión, sino 
que se ubicaría demarcando entre la ciencia y la ideología. La filosofía establecería líneas de demarcación entre lo científico y lo ideológico, a través del enunciamiento de tesis que no serían ni verdaderas ni falsas (carecen de forma de comprobarse) sino serían justas y erróneas y por tanto siempre rectificables. Esto estaría marcado por un establecimiento mucho más cercano entre filosofía, ciencia y política. La justeza. el error y la rectificación de las líneas de demarcación encontrarían un plano mucho más gustoso para la filósofa cubana. Dice: "Criterio de validación de la filosofía fuera de ella, en la práctica política. De tal suerte la filosofía no está encerrada en si misma como la ciencia, que tiene criterios internos de validación. La filosofía actúa en una coyuntura política, ideológica y teórica" (1985: 145). A pesar de ello no dejará de criticarlo al considerar que sigue actuando una concepción unilateral, en donde un polo tiene la posibilidad de determinar a los otros. En términos teóricos se deja atrás el epistemologicismo y se abre paso al relativismo. En un cambio radical del discurso de la propia filósofa escribe: "Althusser pierde de vista que la filosofía marxista-leninista se diferencia del resto del pensamiento filosófico pre-marxista y burgués contemporáneo por su carácter consecuentemente científico y por su partidismo objetivo, esto es, por la integración dialéctica de elementos cognoscitivos e ideológico-valorativos" (1985: 147).

Ambos momentos de la crítica sin embargo se complementan. Desde el punto de vista de la autora tanto Althusser como sus seguidores en América Latina cometen graves errores metodológicos, teóricos, pero sobre todo ideológicos. Su valoración sobre el conjunto de la obra tiene como eje articulador una crítica "ortodoxa" es decir, desde la cosmovisión que presume el Dia-Mat, bastante complejizado con el conocimiento de la llamada lógica dialéctica que la autora conoce bien. Sin embargo con respecto al periodo anterior se denota un retroceso. Frente al periodo de recepción durante el periodo de independencia intelectual y política anterior, la recaída en la ortodoxia soviética es perfectamente visible. Althusser es un hereje a sus ojos al destronar la ortodoxia y sus pilares: la negación de una filosofía totalizante, la idea del marxismo como comprensión omnicomprensiva, el lugar especial de la epistemología, la cual la autora no comprende fuera del resto de las partes: el método, la ideología, la ciencia: la totalidad totalizada.

La influencia soviética en esta parte de la historia de Cuba es de todos conocida. La integración al CAME, la no condena a agresiones soviéticas a otros espacios socialistas, la subordinación a una visión exclusiva de construcción del socialismo -mercado planificado, partido comunista centralizado- entre 
otros elementos son quizá la punta de lanza para entender lo que en el terreno teórico se observa. Aunque de un refinado conocimiento de la filosofía soviética, la autora gravita justamente en una cierta ortodoxia, la soviética, una manera muy peculiar de entender el marxismo. Peculiar manera que no soporta otras distintas. Esto es justamente lo que limita la crítica de una filósofa tan importante y que a tantas generaciones -en los setenta y hasta mediados de los ochenta- influyó. Quede pues como uno de los momentos más relevantes de la recepción crítica del althusserianismo en Cuba.

\section{Mito Y REALIDAD DE ALTHUSSER}

Finalmente daremos entrada a una obra reciente, producida a mediados de los años noventa y hasta nuestros días. Ella es la que aparece bajo la firma de María del Pilar Díaz Castañón, una respetada filósofa de la Universidad de La Habana. Díaz expone en un artículo muy valioso para esta investigación que existió el proyecto de exponer el conjunto de sus investigaciones en torno a Althusser en un libro titulado La imaginación al poder: ensayo sobre el marxismo althusseriano, libro que se perdió en algún acontecimiento natural, según cuenta la autora.

La exposición de la filosofía althusseriana que realiza Díaz se encuentra tanto en un capítulo de su libro Ideología y Revolución cómo en el texto "Louis Althusser: mito y realidad", sobre éste último nos concentraremos para exponer los puntos más importantes, mientras que del capítulo señalado referiremos la interpretación del término de ideología que resulta crucial para el estudio que hace la autora de los primeros años de la revolución cubana.

El primer señalamiento de la autora es de sorpresa al encontrar aún en pleno siglo XXI las mismas críticas comunes del pensamiento althusseriano. Particularmente refiere a las que Néstor Kohan ha realizado en relación con el concepto de ciencia que el filósofo francés tenía. Posteriormente encuadra el marco de la producción althusseriana, no sólo al delimitar algunas problemáticas muy específicas: como ser un autor que formara "escuelas" en vida, con la consiguiente fama de sus discípulos, como la de ser una obra que tiene distintas facetas y que dichas facetas se engarzan a una coyuntura teórica pero sobre todo política. Sin esas consideraciones, esto es, la de desmarcar la producción de su escuela de la de él, como la de insertarla en coyunturas determinadas, la autora considera que no se puede realizar cualquier crítica a la obra. Así, gran parte del texto está dedicado a explorar la coyuntura francesa de los años sesenta, resaltando la importancia de un 
contexto cultural e ideológica irrepetible y que caracterizaron el surgimiento de la escuela. Posteriormente a ello realiza un primer corte de la obra de Althusser, el que ubica como un "primer" momento, el más famoso, el articulado con respecto a la obra Por Marx cuyo eje es la relación entre ciencia e ideología: "En ella caracteriza el surgimiento del marxismo como resultado de un "corte epistemológico" cuya consecuencia es la aparición de dos disciplinas simultáneas: la filosofía, o teoría de las prácticas teóricas, y el materialismo histórico o ciencia de la historia" (Díaz, 2010: 102)

A partir de ello la autora detecta algunas de las falencias de Althusser, remarcando ante todo dos: la influencia del pensamiento denominado estructuralismo, como del psicoanálisis lacaniano, así como una ausencia, la del filósofo alemán Hegel. Para la autora la ausencia de la obra de Hegel es "huella del viejo estilo de pensamiento dogmático que quiere superar". Pero además de ello le da una interpretación unilateral al concepto de sobre-determinación (en las ediciones cubanas y la autora lo mantiene, la "super-determinación") cuya especificidad, según su propia interpretación recae en que "Supone la subordinación de un polo al otro, lo que excluye toda autonegatividad y presuposición real de los elementos que componen una relación de contradicción. Nadie puede repudiar impunemente la dialéctica" (Díaz, 2010). De este segmento fundamental de la interpretación habría que destacar dos cosas. La primera es que la autora no hace mención de los trabajos juveniles de Althusser sobre Hegel, que aún no están traducidos, pero ya circulan en idioma francés hace unos años. Por el otro es que contrario a todas las lecturas del concepto de sobre-determinación, en dicho concepto se jugaría la pluralidad de contradicciones y no la unilateralidad. Es cierto, aunque no en esta parte de la obra de Althusser, que la propia dialéctica, hegeliana o marxista, será puesta en cuestión, por comprometer siempre una visión teleológica en su despliegue.

El rechazo del idealismo y no sólo de Hegel lleva a la autora a pronunciarse en torno a otro de los tópicos más desarrollados por la crítica filosófica, el del humanismo. A este respecto hay que decir que la autora enuncia un juicio bastante mesurado y digno de citarse, Althusser, escribe la autora: "declara que Marx no postuló jamás un humanismo abstracto, sino bien concreto, referido al hombre socialmente entendido y no a una entelequia de valores espirituales inmutables. La explicación fue desoída, y el intenso debate giró en torno a la provocativa formulación: Marx era, teóricamente, antihumanista." (Díaz, 2010: 103) Mesurado juicio que no compromete lo escrito con lo no escrito, ni lleva agua para el molino. Al contrario, las 
polémicas como la del humanismo o el rechazo al historicismo, dice Díaz, se jugaron en territorios ajenos al de la filosofía, como fueron, en el caso del humanismo, la política (¿cómo se podría declarar anti-humanista un marxista?) y, en el de la crítica del historicismo, con la suposición de un tiempo homogéneo, donde los estadios del desarrollo se siguen progresivamente el uno al otro. En estos temas, se discutió en términos de la disciplina historiográfica, a través de las polémicas con Vilar o Thompson.

Para la autora el "Althusser desconocido", curiosamente el que se expondría con fuerza a partir del Curso de Filosofía para científicos y no con el que ahora conoceríamos propiamente como el último Althusser -en su relectura de la tradición materialista con Spinoza y Maquiavelo o en diálogo con Rousseau o el psicoanálisis- sería el que habría, con sus salvedades que releer. Nota cierto avance al dejar de ubicar a la filosofía como lo idéntico a la ideología, al quitar el cientificismo extremo y al colocar a la propia filosofía como la encargada de demarcar entre ciencia e ideología: "Aunque establece que la filosofía demarca también en su propio interior, el autor solo muestra las diferencias filosofía-ciencia, pero no filosofía-ideología, que es solo una negación abstracta de la ciencia" (1985: 105). Estos son límites, a pesar del avance. Al final la justeza de una posición filosófica (cuya labor sería demarcar entre ciencia e ideología) se da a través de la práctica, lo cual haría reducir lo filosófico a la política. Al final tendríamos aquello que el propio francés quería desechar o corregir, "la filosofía como ideología política".

Sobre el tema de la ideología hay que decir algunas palabras más. Contrastándola con otras propuestas clásicas y contemporáneas Díaz observa el desarrollo del concepto de Aparatos Ideológicos de Estado. Aunque valora el aporte considera que "Althusser sugiere una idea cuyo alcance no puede explorar; dado el modo en que reproduce las premisas dogmáticas en las que se formó" (Díaz, 2004: 49). Refiere primero a la repetición de la dicotomía entre ideología dominante y dominada, que olvidando elementos históricos -como el hábito y la costumbre- que exceden a dicha dicotomía. Critica también que la teoría de la ideología de Althusser se asentaría en una concepción mecánica de la totalidad (aquella que comparece como "estructurada y ya dada") y la historia. Contrasta además mientras que algunas ideas similares se encuentran en Gramsci (éste buscaba la revolución), en tanto Althusser apuntaba a comprender el mecanismo de estabilidad. Junto a estos elementos, Díaz, al igual que Rodríguez, realizan una valoración del althusserianismo en México, tema que tendrá que ser explorado con detenimiento en otro momento. 


\section{ALTHUSSER Y LA REVOLUCIÓN CUBANA}

En un estudio reciente el historiador español Kepa Artaraz expone las principales vías de acceso de aquello que se dio a conocer como "Nueva Izquierda" en Europa occidental en su curso de recepción en Cuba. Analizando los casos de Inglaterra, Estados Unidos y Francia, descubre que los principales vínculos políticos e intelectuales de la revolución fueron justamente con este país. Artaraz considera que los intelectuales franceses fueron los más militantes de dicha causa. Sin embargo no sólo desentraña las figuras, los periódicos y las revistas que desde Europa pusieron énfasis en el caso cubano. Al referirse a la contraparte encuentra que la revista Pensamiento Crítico sería la máxima expresión de una "Nueva Izquierda" cubana. Si bien el término es siempre ambiguo y el autor lo señala, es posible inferir ello a partir de la ruptura de marcos conceptuales y de cánones teóricos hasta entonces bien asentados en los partidos comunistas.

En dicho estudio comparativo de experiencias tan disímiles, pero tan unificadas por un espíritu creativo, colectivo y revolucionario llega a señalar que "los trabajos de Althusser dominaron las páginas de las revistas New Left Review y Pensamiento Crítico de finales de los 60" (Artaraz, 2011: 87). Si bien podríamos matizar esta afirmación, lo cierto es que el sentido es claro: el pensamiento francés fue quizá el más productivo. Recordando a Gabriel Albiac podríamos decir que discutir el marxismo en los años sesenta era en gran medida discutir a Althusser. Así lo demuestran en gran medida las obras de aquella época de autores tan diversos como Adolfo Sánchez Vázquez, León Rozitchner, Franz Hinkelammert, en América Latina, y en Europa, Alex Callinicos, Ernest Mandel, Perry Anderson, E.P Thompson, Henri Lefebvre, Roger Garaudy, por mencionar sólo a los más conocidos.

Los jóvenes revolucionarios e intelectuales de aquella época tomaron al toro por los cuernos y produjeron algunas de las principales herramientas de difusión y discusión del marxismo. Junto a ello elaboraron una severa crítica de aquello que no consideraron apropiado. Althusser les permitió en gran medida plantearse una des-identificación de la obra marxista en sus etapas. Salir de la forma manual y pasar a una historización del pensamiento de Marx de acuerdo a su contexto y a las problemáticas específicas les planteo un horizonte novedoso, por increíble que parezca desconocido para los cánones. Pequeña contribución quizá, pero fundamental para replantear el horizonte. 
Después de aquellos años y con el retroceso en la producción de un pensar independiente, sobrevino la época de la sovietización del pensamiento. Dicha época está marcada en lo que refiere a Althusser por la presencia de la importante filósofa Zaira Rodríguez, quien además de reivindicar de manera seria el pensamiento en el que estaba formada -la filosofía soviética- también leyó atentamente al filósofo francés. Lo hacía por dos razones, en un nivel teórico discutió con las conclusiones que se seguían de los distintos momentos de la obra, cuestión importante pues en aquel momento Althusser había ya caído en desgracia. Pero lo hizo, en segundo lugar, por refutar a quienes "se habían apartado del camino de Marx" al seguir a Althusser. Especial atención tuvo en este sentido las crítica que dirigió a Raúl Olmedo y Enrique González Rojo en México.

En un tono similar María del Pilar Castañón realizó una operación a la de Rodríguez: no sólo leyó críticamente a Althusser -aunque de forma más matizada- sino que también se esforzó por combatir la interpretación "mexicana" que hicieron autores como los ya mencionados Olmedo y González Rojo, además de Carlos Pereyra (Díaz y Ayús, 1992: 47-68). La evaluación de la obra del filósofo francés es mucho más mesurada. Pone atención a los cortes en la propia obra. Se distancia de las críticas actuales que huelen a un desconocimiento de la obra, pero también insiste en temas relevantes, particularmente en la ideología.

Este panorama breve, sucinto y sintético que hemos querido dar devela un campo de investigación que se abre. La necesidad de re-contar la historia y problematizar momentos cruciales es una condición de nuestra propia coyuntura. Cuba fue, por su revolución, el lugar de cruce de cientos de intelectuales y militantes de las más variadas tendencias. Aunque Althusser nunca salió de Europa, es viable pensar que en su quizá limitado panorama extra-europeo Cuba guardaba un lugar importante. Dice, y con ello queremos finalizar, en una carta que mandó a Martínez Heredia en abril de 1967: "La Cuba socialista me hace el honor más grande de mi vida al traducir esos textos y como pude ver en la pequeña nota que acompaña la traducción de Por Marx al distribuirlo gratuitamente a los estudiantes. Sin duda alguna vez visitaré su hermoso país..."

1 Conferencia de Fernando Martínez Heredia en el ciclo "Debates y combates del pensamiento crítico en Cuba" realizada en el CEIICH, de la UNAM. https://www.youtube.com/ watch? $\mathrm{v}=\mathrm{BN} 4 \mathrm{Q}$ da7eUM 


\section{BIBLIOGRAFÍA}

ARTARAZ, K. (2011); Cuba y la nueva izquierda: una relación que marco los años 60. Buenos Aires: Capital Intelectual, 2011.

DÍAZ CASTAÑóN, M. (2004); Ideología y revolución: Cuba, 1959-1962. La Habana: Ciencias Sociales, , (2010); “Mito y realidad de Althusser" en Temas, Octubre-diciembre, La Habana

DÍAZ CASTAÑÓN, M y AYÚS REYES, R. (1992); “México 60: ¿por qué Althusser?”, en Islas, La Habana, Cuba, No. 101, pp. 47-68.

GÓMEZ VÁZQUEZ, N. (2002); "El pensamiento althusseriano entre los cubanos, sus primeros acercamientos” en Utopía, Universidad de Popayán, No. 15, marzo.

, (2006); "La divulgación del marxismo en la revista Pensamiento crítico", en Marxismo y Revolución La Habana, Ciencias Sociales.

GÓNZALEZ ARÓSTEGUI, M. (2006); “Las Plenarias Nacionales Universitarias de profesores de Filosofía: reflexiones y polémicas en su entorno” en Marxismo y Revolución. La Habana: Ciencias Sociales.

KOHAN, N. (2006); "Pensamiento crítico y el debate por las ciencias sociales en el seno de la revolución cubana" en et. al. Crítica y teoría en el pensamiento latinoamericano. Buenos Aires; CLACSO.

MARTÍNEZ L. (2006); Los hijos de Saturno: intelectuales y revolución en Cuba, FLACSO, México, 2006.

MARTÍNEZ HEREDIA, F. (1968); “El Ejercicio del pensar”, Lecturas de Filosofía T. II, La Habana, Cuba.

, (1968b); “Orígenes del marxismo", Lecturas de Filosofía T.I, La Habana, Cuba, 1968.

, (1970); “El marxismo de Althusser”, en Pensamiento crítico No. 36, enero de 1970, La Habana, pp. 210-218.

MARTÍNEZ HEREDIA, F y ACANDA J. (1997); Filosofar con el martillo. La Habana: Centro de Investigaciones Juan Marinello, 1997.

MORALES, C. (2008); Pensadores del Acontecimiento. México: Siglo XXI, 2008.

NAVARRETE, L. (2012); “El sujeto heterodoxo en la Revolución cubana: una mirada desde la novela Las iniciales de la tierra" en Correa Chiarotti, María Guadalupe (coord.), Itinerarios y perspectivas de la literatura nuestramericana, México, EON-UNAM, 2012, pp.17-42

POGOlOTTI, G. (2006); “Los polémicos sesenta” en Polémicas culturales de los 60. La Habana: Letras Cubanas. 
POPOVICH, A. (2012); "La recepción de Althusser por la Nueva Izquierda Argentina: el caso de Los Libros (1969-1976)” en Aimer Granados (coord.), Las revistas en la historia intelectual de América Latina: política, sociedad y cultura. México: UAM-C-JP.

RODRÍGUEZ M; RAMÍREZ J; CORTÉS C, “Lecturas de Althusser en Chile (notas preliminares)" en Ramal. Revista de Filosofía y Crítica. Santiago de Chile, $\mathrm{N}^{\circ} 1,2013$.

RODRÍGUEZ PEDRO, P. (s/f); "Valoración de las tradiciones filosóficas cubanas desde un punto de vista marxista: El Marxismo y la cultura cubana. Apuntes al vuelo", en Teoría, crítica e historia, [http://www.ensayistas.org/ critica/cuba/fornet/rodriguez.htm]

RODRÍGUEZ UGIDOS, Z. (1985); Filosofía, ciencia y valor, La Habana, Ciencias Sociales.

SÁEZ, H. (2012); "La tesis de filosofía del sub Marcos: una lectura de Althusser" en Pacarina del Sur, Año 3, núm. 12, julio-septiembre de 2012

STARCENBAUM M. (2011a); "El marxismo incómodo: Althusser en la experiencia de pasado y presente (1965-1983)" en Revista Izquierdas, Santiago de Chile [http://132.248.9.34/hevila/IzquierdasSantiago/2011/no11/3.pdf]

(2011b); "Althusserianismo y lucha armada: Luis María Aguirre, Mauricio Malamud y la recepción de Althusser en los orígenes de las FAL." Presentado en XIII Jornadas Interescuelas-Departamentos de Historia, Catamarca, Argentina

[http://eltopoblindado.com/files/Articulos/08.\%20Organizaciones\%20de\%20 origen $\% 20$ frentista/Starcenbaum, \%20Marcelo.\%20Althusserianismo $\% 20$ y\%20lucha\%20armada.pdf]

VALDERRAMA, M. (1988); "Althusser y el marxismo latinoamericano. Notas para una genealogía del (post)marxismo en América Latina” en Mapocho: revista de humanidades y Ciencias Sociales, Santiago de Chile.

[http://www.cervantesvirtual.com/obra-visor/mapocho-revista-de-humanidades-y-ciencias-sociales--0/html/ff1e7926-82b1-11df-acc7002185ce6064_36.htm\#I_15_]

\section{OTROS}

"Cuba y el pensamiento crítico: entrevista con Fernando Martínez Heredia" en Dialéktica, Buenos Aires, No. 3/4, 1993, p. 78.

Conferencia de Fernando Martínez Heredia en el ciclo "Debates y combates del pensamiento crítico en Cuba" realizada en el CEIICH, de la UNAM. https://www.youtube.com/watch?v=BN4Qeda7eUM 